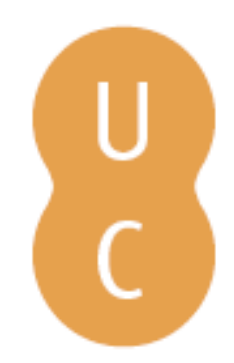

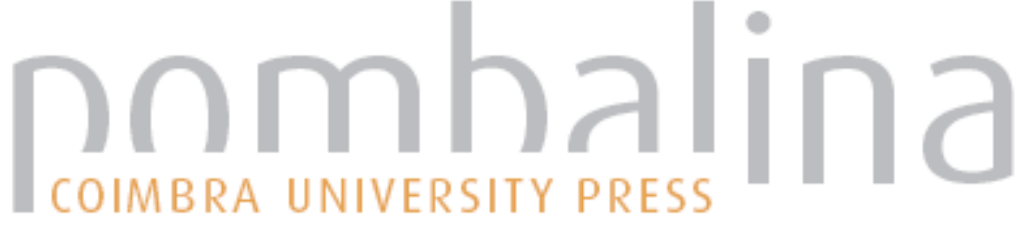

\section{Utensílios de informação: menos é mais (mais ou menos)}

\author{
Autor(es): $\quad$ Buxton, William
}

Publicado por: Imprensa da Universidade de Coimbra; Gradiva

URL

persistente: URI:http://hdl.handle.net/10316.2/32701

DOI: $\quad$ DOI:http://dx.doi.org/10.14195/978-989-26-0389-6_19

Accessed : $\quad$ 26-Apr-2023 13:37:29

A navegação consulta e descarregamento dos títulos inseridos nas Bibliotecas Digitais UC Digitalis, UC Pombalina e UC Impactum, pressupõem a aceitação plena e sem reservas dos Termos e Condições de Uso destas Bibliotecas Digitais, disponíveis em https://digitalis.uc.pt/pt-pt/termos.

Conforme exposto nos referidos Termos e Condições de Uso, o descarregamento de títulos de acesso restrito requer uma licença válida de autorização devendo o utilizador aceder ao(s) documento(s) a partir de um endereço de IP da instituição detentora da supramencionada licença.

Ao utilizador é apenas permitido o descarregamento para uso pessoal, pelo que o emprego do(s) título(s) descarregado(s) para outro fim, designadamente comercial, carece de autorização do respetivo autor ou editor da obra.

Na medida em que todas as obras da UC Digitalis se encontram protegidas pelo Código do Direito de Autor e Direitos Conexos e demais legislação aplicável, toda a cópia, parcial ou total, deste documento, nos casos em que é legalmente admitida, deverá conter ou fazer-se acompanhar por este aviso.

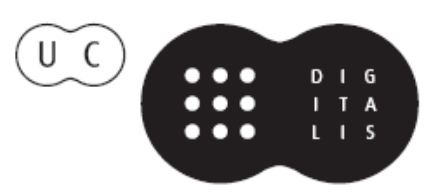


C I E N C I A I B E R T A

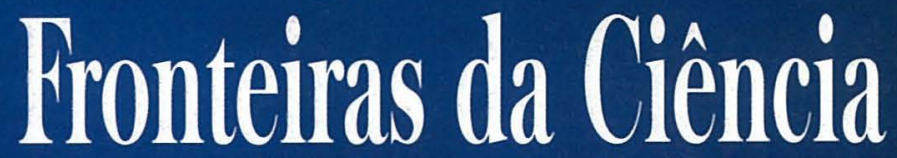

Desenvolvimentos Recentes - Desafios Futuros

RUI FAUSTO • CARLOS FIOLHAIS • JOÃO FILPE QUURRÓ

Coordenadores

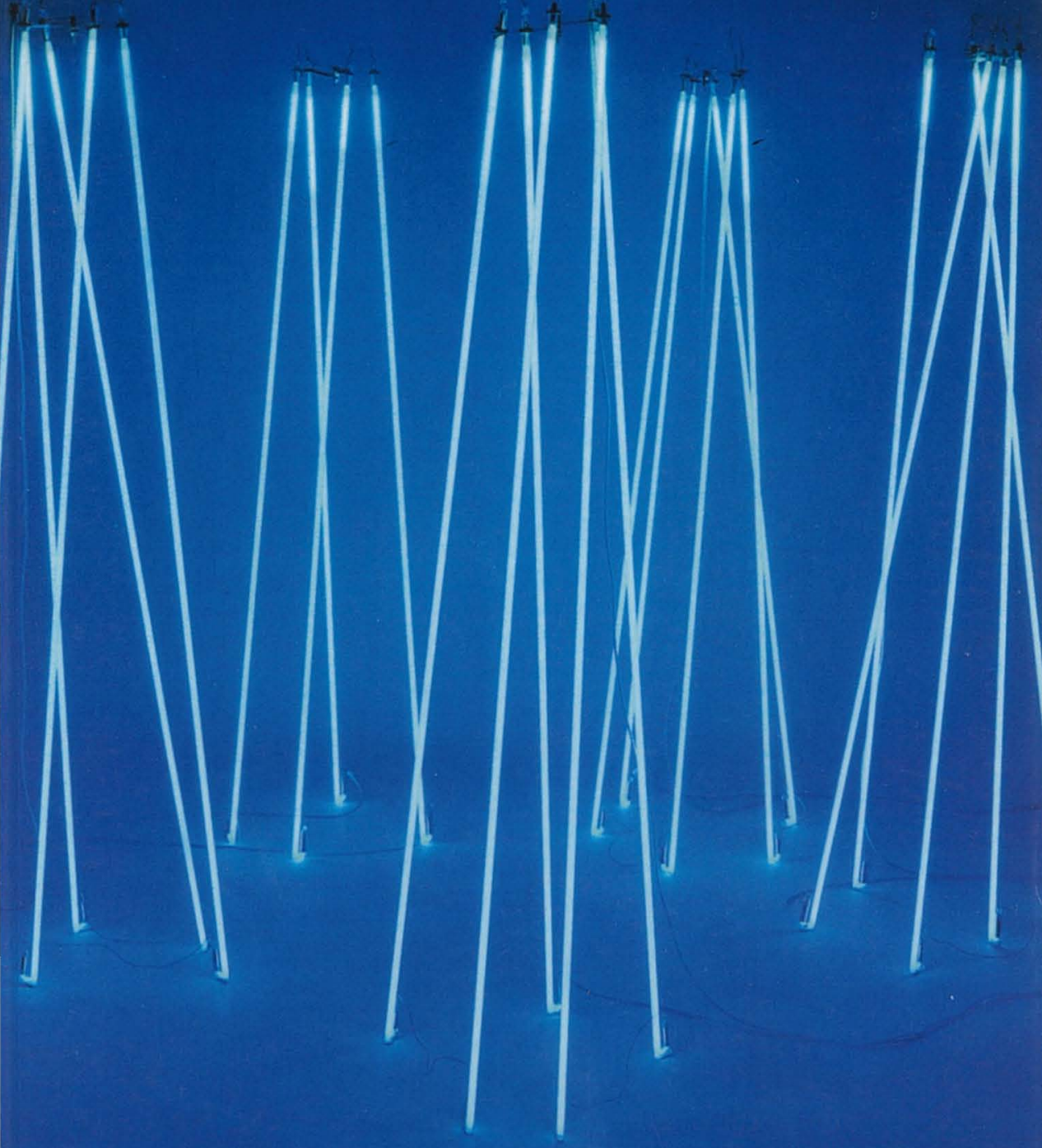

gradiva - Imprensa da Universidade de Coimbra 
(Página deixada propositadamente em branco) 


\section{RUI FAUSTO, CARLOS FIOLHAIS JOÃO FILIPE QUEIRÓ \\ Coordenadores}
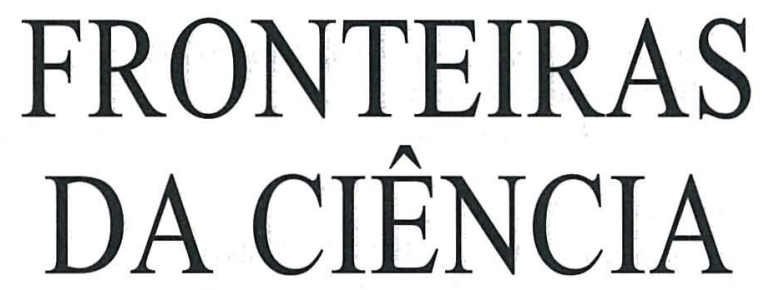

Desenvolvimentos Recentes Desafios Futuros 
(C) Gradiva - Publicações, L. da / Imprensa da Universidade de Coimbra, 2003 Coordenação editorial: Rui Fausto, Carlos Fiolhais e João Filipe Queiró Tradução: Jean Burrows, Vivien Burrows, Rui Fausto, Carlos Fiolhais e João Filipe Queiró

Revisão do texto: Isabel Pedrome

Capa: António Barros [Imprensa da Universidade. Coimbra], sobre imagem de «Águas Vivas», escultura de Silvestre Pestana, 2001

Foto: António Alves; Infografia: ESTÍMULUS [design]; Cortesia: Galeria Alvarez-Arte Contemporânea

Paginação: António Resende e Paula Isabel Jorge

Impressão e acabamento: G.C. - Gráfica de Coimbra, L. ${ }^{d a}$

Reservados os direitos para Portugal por:

Gradiva - Publicações, L. ${ }^{\text {da }}$ e Imprensa da Universidade de Coimbra

Gradiva - Publicações, L.da

Rua Almeida e Sousa, 21, r/c, esq.•1399-041 Lisboa

Telefs. $213974067 / 8 \cdot 213971357 \cdot 213953470$

Fax $213953471 \cdot$ Email: gradiva@ip.pt

URL: http://www.gradiva.pt

Imprensa da Universidade de Coimbra

Rua Antero de Quental, 195 • 3000-033 Coimbra

Telefs. 351239853110

Fax 3512398531 19・e-mail: fjrpress@ci.uc.pt

URL: http://www.imp.uc.pt

ISBN: 972-662-923-3

1." edição: Agosto de 2003

Depósito legal n. ${ }^{\circ} 199$ 463/2003 
William Buxton

Alias / Wavefront Inc.

Toronto

Canadá

\section{Utensílios de informação: menos é mais (mais ou menos)}

Vou falar-vos sobre tecnologia. E vou falar sobre sociologia, antropologia e psicologia. Um dos livros de que menos gosto e que só por isso vou referir é de Nicholas Negroponte e chama-se Being Digital. Que título estúpido para um livro! - a questão não é precisamente ser-se humano? E é sobre isso que desejo falar, porque, se a tecnologia é tão maravilhosa, e se progredimos tanto, e se a inteligência artificial é uma coisa assim tão boa, então porque não podem os computadores adaptar-se às pessoas em vez de terem as pessoas de se adaptar aos computadores? Assim, desejo falar de design e estar diante de vós como um designer e não como um cientista. Podemos aplicar a sociologia, a antropologia e a psicologia ao design e assim fazer uma abordagem com o humano no centro.

Os quadros das salas de aula foram progressivamente introduzidos na segunda metade do século XIX no então chamado Alto Canadá. Ao longo de um período de cerca de dez anos os quadros começaram a aparecer na sala de aula. Poderão perguntar: «Porque é que convidámos este tipo a vir do Canadá para nos dizer uma coisa destas, que não tem nada que ver com ciência nem com tecnologia?» $\mathrm{E}$ a minha resposta é que tem muito que ver com ciência e com tecnologia. Talvez hoje o maior problema em tecnologia seja que confundimos invenção com investigação, esquecendo que a ideia de desenvolvimento e evolução tem duas componentes: uma é o estudo e a outra é a invenção. Só olhando para trás, e estudando, é que 
poderemos tomar boas decisões no futuro. Gostaria que se interrogassem sobre o que existia antes do quadro. A resposta é a ardósia, o quadro pequeno. Trata-se exactamente da mesma tecnologia, do mesmo interface com o utilizador, a mesma operação de apagar, o mesmo editor de texto. A «única» diferença é que o quadro é maior e está num sítio diferente. Mas essa pequena diferença significou, na minha opinião, que a introdução dessa tecnologia - que é na realidade apenas uma transformação de uma tecnologia - teve mais impacto na aprendizagem e na educação que a introdução de qualquer outra tecnologia desde então (incluindo a invenção do papel barato, porque, nessa época, não existiam fábricas de papel e o papel era caro), ou a introdução de todos os PC e a Internet juntos. Aquela tecnologia tinha uma diferença. Mas observem que a diferença era uma diferença de utilização. Era uma questão de tamanho ou escala. Era uma questão do lugar onde o meio técnico era colocado.

Este respeito das relações espaço-função-distância não tinha que ver com a própria tecnologia. Se uma tal mudança e um tal impacto, em função do objectivo de uma tecnologia na sala de aula, foram conseguidos simplesmente repensando a localização e a escala, então e as tecnologias que temos hoje? Na verdade, eu defenderia fortemente que o uso de um projector como este, com um ponteiro luminoso barato, para transformar a parede da sala de aula num écrã electrónico, poderia ter mais impacto do que pôr um Power Macintosh ou um Pentium na secretária de cada estudante. E, no entanto, e mesmo que isso seja só $20 \%$ provável, há $0 \%$ do dinheiro na computação educacional dedicado a essa questão porque temos estes antolhos que nos dizem que «os computadores e a Internet são a resposta para a questão dos computadores na educação e nem sequer vamos pensar no quadro». É por isso que eu gosto da história: podemos aprender lições sem termos os nossos preconceitos e depois ver se eles são válidos. Este é o tema da minha palestra.

Aqui está um computador e um interface gráfico. Pergunto: em que ano é que esta fotografia foi tirada? Ou em que década? Na realidade é de 1982: isto é uma workstation Xerox Star 8010. Tem mais pixels, funciona melhor e tem um interface gráfico melhor do que uma máquina com Windows 95. Na minha disciplina - o design de computadores e workstations, em que as coisas mudam tão depressa e a tecnologia é tão maravilhosa - houve um progresso intelectual nulo em quase 20 anos. Não aprendemos nada. $\mathrm{O}$ Windows 95 não está tão bem construído como o interface gráfico da Xerox Star. E a única coisa que está a mudar não é a tecnologia: esta está mais rápida e mais barata, mas que interessa isso? Sob uma perspectiva intelectual, do modo como construímos as coisas, e no modelo conceptual, nada mudou e não tem havido progresso. 
Eu sou pago para não saber como se usam computadores e a única coisa realmente inteligente que alguma vez fiz foi convencer as pessoas da tecnologia de que isso era culpa delas e não minha. É preciso mudar o design.

A última coisa de que me vão ouvir falar é a maneira de tornar os computadores fáceis de usar. Isso é um objectivo muito estúpido e, de um ponto de vista científico, está muito mal formulado. Uma coisa que sei, como cientista, é que um problema bem formulado está já meio resolvido. Não se pode medir o que significa fazer os computadores fáceis de usar. É uma expressão sem significado; é um slogan publicitário. Não é algo de preciso. A maneira correcta de falar da complexidade dos interfaces com o utente, e numa forma que podemos levar à prática, consiste em dizer que o objectivo é acelerar o processo através do qual um principiante consegue trabalhar como um especialista.

No meu trabalho concebo sistemas para animações, para pessoas que trabalham com imagens: presumo que o utente tem formação artística, que é um especialista. Portanto a questão agora é como acelerar o processo através do qual um principiante passa a especialista no uso da tecnologia, de forma que todos os recursos cognitivos do utente possam ser dedicados ao quê e não ao como. O que eu sei é que, antes de mais, se a facilidade de utilização fosse uma medida com significado, o violino estaria obsoleto, o piano estaria obsoleto, o atacador de sapatos estaria obsoleto e o automóvel estaria obsoleto, porque nenhum deles é fácil de usar. A propósito de lápis - toda a gente diz «Porque é que os computadores não podem ser tão fáceis de usar como um lápis?» Ora a minha mulher é artista, passou 20 anos a aprender a usar um lápis e ainda está a aprender! Picasso diria que nunca aprendeu completamente a usar um lápis; um lápis é fácil de usar? Não; é fácil pegar nele, é fácil transportá-lo, mas não é fácil de usar. Portanto a questão não é a facilidade de utilização; a questão é, em primeiro lugar, «Vale a pena utilizar?», e depois: «Como posso eu não desperdiçar o meu tempo?»

O que significa ser principiante e ser especialista? A diferença tem que ver com competência. Pergunta-se: «o que é competência?» Se eu quero saber se o trabalho do especialista é um trabalho competente, é melhor saber de que ponto estou a partir, porque então conheço os dois lados da questão. Qual é, então, o oposto de competência? A resposta é: a resolução de problemas. De um ponto de vista psicológico, quando se é competente e se está a executar uma tarefa não se está a resolver um problema: está a trabalhar segundo o que se chama automatismo. Quando se é principiante e sem competência, pelo contrário, tem de se prestar atenção à tarefa, ela consome recursos cognitivos e está-se a resolver um problema, está-se a fazer planeamento, e por aí fora. 
Portanto, o que nós estamos a tentar fazer neste processo é afastar-nos de um comportamento de resolução de problemas, que consome recursos cognitivos, que interfere com os recursos cognitivos dedicados ao trabalho principal. E isso é mau é disso que nos queremos livrar. Muitas pessoas na minha profissão dizem: «Isso é um disparate; tudo o que há a fazer é educar os utentes, com melhores cursos, melhor documentação.» Mas não é verdade: isso é simplesmente uma desculpa de maus designers. $\mathrm{O}$ negócio chama-se «corrigir gralhas nos manuais», não é? Os manuais do meu computador pesam mais e têm o triplo do volume do próprio computador (a propósito, o mesmo se passa com o Boeing 747). Posso dizer-vos algo sobre as razões por que o design é mau, e esta é uma afirmação que fiz em Stanford, no MIT, no Georgia Institute of Technology e em todas as grandes universidades da América do Norte. A afirmação é: a razão por que os computadores são tão mal concebidos é que $98 \%$ dos engenheiros informáticos acabam os cursos sem nunca terem escrito um programa que fosse usado por outro ser humano, e sobretudo sem nunca terem sido avaliados pela sua capacidade para o fazer.

Temos assim um problema com a formação, mas não é a formação dos utentes dos computadores, é a iliteracia formativa das pessoas estúpidas que estão a conceber estes sistemas, porque elas não têm qualquer formação e qualificação na tecnologia que é essencial para o design, a saber, a tecnologia do ser humano. Porque não é o software que importa, é o wetware - os $90 \%$ do cérebro que são água. E enquanto esquecermos isso nunca sairemos da situação em que estamos: continuaremos a ter sistemas muito mal feitos e a causar problemas, tornando o mundo mais complexo, em vez de mais simples.

Eis a lei de Buxton da conservação das competências: "Toda a competência superior que se aprende depois da puberdade é adquirida à custa de uma competência previamente aprendida.» É por isto que não se pode dizer «Eu dou-lhe formação», ou «Eu trato disso na documentação», porque se eu fizer um mau design e depois mandar o utente para a escola durante dois meses a fim de ganhar a competência para trabalhar com esse sistema o melhor é esquecer o que ele fazia antes. Demonstração: há 24 horas num dia, a prática necessária à aquisição de competências segue uma lei exponencial, é preciso dormir, $Q E D$. Portanto a conservação das competências é uma verdadeira lei. Os recursos cognitivos, a aprendizagem e o tempo são finitos e não podemos desperdiçá-los sem boas razões. E isto tanto vale para os indivíduos como para as sociedades.

Toda a gente aprende a guiar automóveis, mas já ninguém sabe lidar com cavalos. O meu avô rir-se-ia do tempo que eu gasto a aprender a montar a cavalo porque isso é uma cultura e eu perdi-a. 
Falemos agora de complexidade e limitações humanas. Esta é a parte técnica. O primeiro gráfico científico que tenho refere-se à lei de Moore: para vos ajudar, ela diz que vai haver mais tecnologia amanhã do que há hoje.

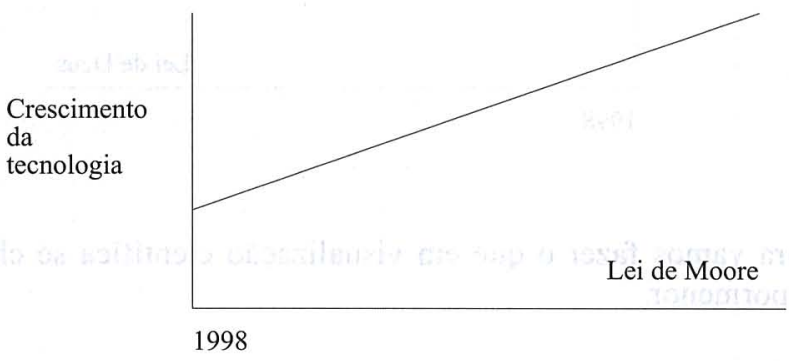

Agora vejamos a lei de Buxton. Ela diz que a funcionalidade prometida, a funcionalidade que vamos tentar proporcionar com a tecnologia, vai aumentar em proporção com a lei de Moore. Em termos simples, diz que vai haver mais funcionalidade amanhã do que há hoje.

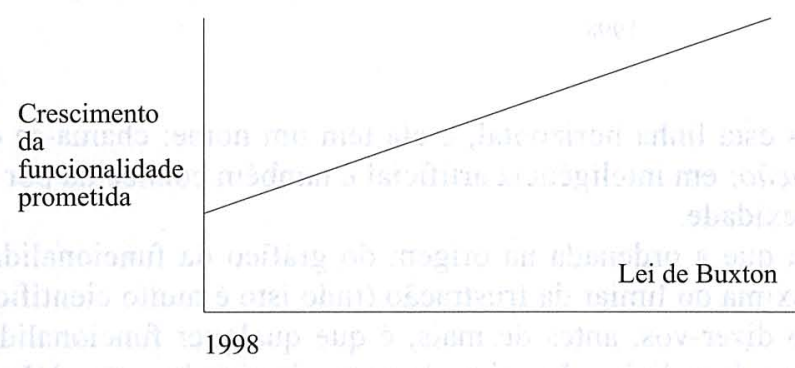

A lei seguinte chama-se lei de Deus. Ela mostra o aumento das capacidades humanas e trata basicamente do seguinte: como está a variar a velocidade dos neurónios, como está a variar a nossa memória? Podemos representar essa variação por uma linha horizontal, mas de facto há uma descida. Qualquer engenheiro é capaz de referir a lei de Moore, mas qual é a lei mais importante? E qual deveria influenciar mais o design? Esta última, claro. 


\section{Crescimento \\ da \\ capacidade humana}

\section{Lei de Deus}

1998

E agora vamos fazer o que em visualização científica se chama um zoom de pormenor.

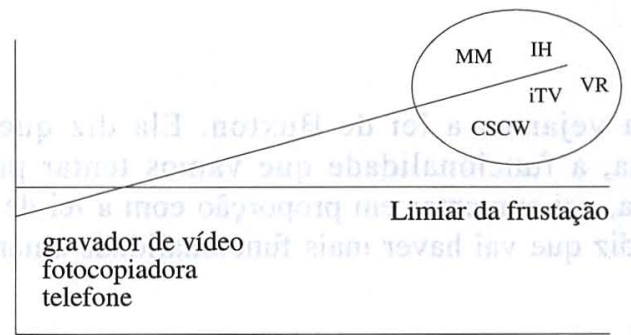

1998

Vemos esta linha horizontal, e ela tem um nome: chama-se o limiar da frustração; em inteligência artificial é também conhecida por barreira da complexidade.

Notem que a ordenada na origem do gráfico da funcionalidade está muito próxima do limiar da frustração (tudo isto é muito científico...). O que quero dizer-vos, antes de mais, é que qualquer funcionalidade que esteja acima desta linha não existe do ponto de vista humano. Não importa que esteja no livro de instruções, não importa que esteja no programa, não importa sequer que seja possível demonstrá-la - não existe do ponto de vista humano! Nunca será utilizada. Talvez tenha sido a razão por que eu comprei o aparelho, mas nunca o utilizarei. Falem com um vendedor de fotocopiadoras e ele dir-vos-á quais são as características de uma fotocopiadora e quais delas nunca serão usadas. Ele sabe exactamente qual é a diferença entre as razões pelas quais compramos e o que fazemos com o que compramos. 
Suponhamos que conhecem alguém na Portugal Telecom e telefonam para lá, digamos para o centro de investigação, dizendo: «Quero falar com Fulano». Mas, de propósito, marcaram o número errado e dizem: «Podia transferir a chamada, por favor?». E eles dirão - e isto é assim em qualquer companhia telefónica no mundo - «Sim, mas tome nota do número certo, para o caso de a chamada cair». O que é o mesmo que dizer: «Eu trabalho para o centro de investigação da companhia de telefones, mas não sei usar o telefone.» $\mathrm{O}$ vice-presidente da Xerox para a investigação é um amigo meu, chamado John Stephen Brown, que ficou famoso por fazer vídeos dele próprio e de outros executivos da Xerox a não conseguirem usar as fotocopiadoras da Xerox. O que eu estou a dizer é que, se pensarmos no gravador de vídeo, na fotocopiadora e no telefone, não temos qualquer credibilidade como engenheiros para proporcionar a funcionalidade dos dispositivos multimédia (MM), da auto-estrada da informação (IH), da realidade virtual (VR), da televisão interactiva (iTV), do trabalho em colaboração com apoio computacional (CSCW), porque todos estão acima do limiar. Se eu ainda não consigo conceber um telefone ou uma fotocopiadora ou um gravador de vídeo, como é que vou conseguir conceber aquelas coisas de forma que a funcionalidade fique abaixo do limiar de frustração? E é muito claro, apesar da publicidade, que a penetração dos computadores nas casas e nas empresas está a estabilizar, porque todas as pessoas que foram suficientemente estúpidas, ou corajosas, para comprar este lixo já o compraram, e as pessoas normais não o vão fazer. Isso tem significativas implicações económicas, mas o elemento chave do design é melhorar a funcionalidade e eu acredito que é possível fazê-lo.

O objectivo é acelerar o processo através do qual um principiante consegue trabalhar como um especialista, e isso tem que ver com a aquisição de competências, não só competências cognitivas mas também motoras e sociais.

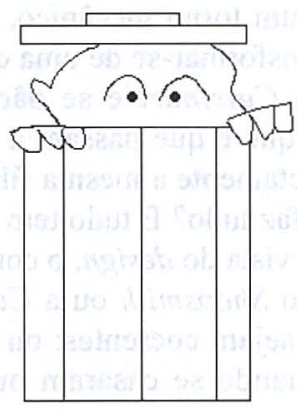

DESPERDÍCIO

DE COMPETÊNCIAS

EXISTENTES 
Nenhuma parte da anatomia humana que está dentro deste caixote do lixo é necessária para trabalhar com um computador. Até estou a ser generoso, porque esta criatura tem dois olhos e um ouvido. Para trabalhar com um computador é preciso ter uma largura de banda de $100 \mathrm{~Hz}$ para o ouvido, não é preciso falar, e de facto só é necessário um olho e esse olho só precisa de ter um cone de visão de cerca de 14 graus, e em geral só precisa de cores primárias saturadas.

O computador de hoje foi feito para Napoleão Bonaparte. Pode usar-se o interface gráfico com a mão esquerda na barriga, como Napoleão, e a única altura em que se usam as duas mãos é quando se escreve, que é uma coisa que eu consigo fazer só com uma mão, com um lápis. Eu sou famoso no mundo dos computadores como a pessoa que teve a incrível visão, intuição e génio de reconhecer que as pessoas têm duas mãos. Que razão estúpida para ser famoso! Mas, seja como for, mostra que há futuro na minha profissão porque qualquer um pode ser famoso.

Vou agora falar-vos da grande mentira. A grande mentira é que estamos num período de convergência. Eu digo-vos que as únicas pessoas que querem saber da convergência são os canalizadores. Para vocês, o que está a acontecer, e a única saída da presente situação, é a divergência. Esse é o tópico seguinte desta palestra.

Pergunto: quantos de vocês cozinham com uma coisa chamada Cuisinart? (A propósito, eles ainda não faliram: www.cuisinart.com.) Eu recebi uma coisa dessas quando casei e já não sei onde pára. Mas ela corta e descasca, ela faz tudo e ninguém a usa porque é preciso mudar de uma função para outra, e todas as peças têm de ser lavadas, e é preciso saber como funciona, etc.

Quantos de vocês fazem carpintaria? Quantos de vocês tệm um aparelho destes? O meu pai tinha um e nunca o usou. Isto chama-se um Shopsmith (a propósito: www.shopsmith.com) e em cinco minutos pode transformar-se de um berbequim num torno mecânico, de uma serra de fio numa serra de dentes... Pode transformar-se de uma coisa noutra. Mas se vocês não cozinham com uma Cuisinart e se não fazem a vossa carpintaria com um Shopsmith, porque é que passam a vida inteira com o vosso computador, que segue exactamente a mesma filosofia de design, a ideia de que um mesmo aparelho faz tudo? E tudo tem de ser feito onde o aparelho está, porque, do ponto de vista do design, o computador pessoal é exactamente a mesma coisa que o Shopsmith ou a Cuisinart. E vocês compram-nos. Portanto, por favor, sejam coerentes: ou começam a usar essas Cuisinarts que receberam quando se casaram ou deitam fora os vossos computadores. 
Essa abordagem ao design é o que eu chamo o super aparelho e o que eu digo é: o mesmo tamanho não pode servir para todos, e serviços diferentes exigem embrulhos diferentes. Em biologia da evolução, um dos axiomas diz que os sistemas especializados levam sempre a melhor sobre os sistemas gerais. E esta evolução é semelhante.

Este canivete suíço é a minha estação de trabalho. Costumo trazê-lo na pasta com os meus papéis. Tem um nível razoável de funcionalidade - tem uma tesoura, um furador, um abre-latas, etc. - e muitos de vocês provavelmente têm um.

Este canivete mais simples é um PDA (personal digital assistant); este dispositivo de ponta só tem três coisas, mas anda sempre comigo, junto com as minhas chaves.

A seguir vem a minha estação de trabalho multimédia. Deu-ma a minha avó quando fui para um acampamento. Tem uma faca, um garfo, uma colher; tem uma serra para madeira e tem uma tesoura. Tem tudo e não serve para nada, a não ser como lastro para um barco. Ninguém anda com uma coisa destas, mesmo que tenha uma. É o que há de mais parecido com o vosso computador pessoal. Olhem para as ferramentas e comecem a contá-las - a propósito, estamos a voltar ao meu exemplo do quadro e façam uma lista dos sítios associados a cada uma dessa funcionalidades: notem que o lugar da serra é na oficina, o da colher e do garfo é na cozinha, a tesoura na sala de costura, o furador no estábulo, o corta-unhas no quarto de banho, o saca-rolhas na sala de jantar.

Se olharmos para as diferentes actividades para as quais temos ferramentas, em quase todos os casos conseguimos descrever o sítio onde essa actividade tem lugar e também o seu contexto social. O design evoluído reflecte essa diversidade, enquanto a abordagem super aparelho, a abordagem Cuisinart, que adoptamos nos computadores pessoais (e na televisão interactiva é quase a mesma coisa) diz que todas essas actividades se juntam no sítio onde se encontra o aparelho. Reparem nas implicações: se tudo for feito no mesmo sítio, no mesmo aparelho, só uma pessoa pode trabalhar de cada vez e só uma coisa pode ser feita de cada vez.

Portanto, mesmo se compraram um computador para escrever coisas sérias para uma revista científica, a vossa mulher pode querer fazer as contas da casa, um filho pode querer fazer o trabalho de casa, outra pode querer navegar na Internet, outra pode querer ouvir música, outra pode querer jogar, etc. Se acham que já se discute sobre quem fica com o comando da televisão, imaginem as batalhas familiares que aí vêm quando todos quiserem usar o computador. Esse é o design que compraram. Esse é o design do lixo que a minha empresa e outras vos dão. Parem de comprar isto! 
A verdade é (isto é uma conjectura) que a utilidade varia com $1 /\left(\right.$ funcionalidade $^{\mathrm{n}}$, com $n$ grande. Mais uma vez estou a ser muito preciso porque sou um matemático, mas esta é a fórmula mais complicada que aqui apresento.

As pessoas nunca falam da utilização, só falam da tecnologia: os aparelhos estão a ficar maiores ou mais pequenos, mais rápidos, mais baratos, estão a ficar em rede. Depois algumas pessoas poderão dizer que os aparelhos vão ser sensíveis à sua localização, tanto em termos absolutos como em relação a outros aparelhos, e talvez venham a ter diferentes dispositivos de input e output. Mas a importância das coisas nesta lista está na ordem exactamente oposta àquela que costuma ser referida.

Agora vou falar da Waternet. A Waternet é uma grande rede integrada. Antigamente tínhamos poços, tínhamos sistemas isolados nas nossas casas, íamos ao poço buscar água e deitávamos fora a água depois de a usarmos em casa. Agora estamos todos ligados e temos esta grande rede unificada que traz água para dentro de casa e a leva para fora de casa. Está tudo unificado e há um monopólio que controla tudo. Se funciona, é invisível; só quando se avaria é que damos por ela. E não nos interessa a quem pertence - nós só pagamos a conta. Mas notem que se pode dizer em que divisão está cada ligação; estas são as estações de trabalho da Waternet, estes são os aparelhos da rede. Mesmo na Waternet os aparelhos não são como uma Cuisinart porque além de esgotos há chuveiros e sei, em relação a cada dispositivo de aspersão, se é para regar o jardim, se é do extintor de incêndios, se é do chuveiro, se é da máquina de lavar: há uma enorme diversidade.

Recordem que eu disse divergência, não convergência. A convergência está na Waternet, até à parede; a divergência está em tudo o que eu vejo e toco. As únicas coisas de que tenho consciência são diversas; temos uma granularidade muito fina de diferenciação. E é muito importante reconhecer, historicamente, tal como com o quadro, que estas coisas nos indicam a direcção para onde o design deve ir. E ninguém confundirá uma banheira com um chuveiro ou com um jacuzzi.

Falei atrás de dispositivos de input e output. Hoje a coisa mais importante em tecnologia é que, neste espírito de o mesmo tamanho para todos, é preciso incluir tudo e da mesma maneira. Eu já disse que os meus clientes são artistas gráficos. Se olharem para uma estação de trabalho vulgar, um computador gráfico - o Macintosh para artistas — os desenhos são feitos com um rato, que é como um sabonete; no meu país, a única altura em que se fazem desenhos com sabonetes é no Dia das Bruxas, quando se escreve nos vidros das janelas. Uma das coisas mais importantes que vão distinguir os computadores são os dispositivos de input e output, 
a forma de fazer a ponte entre o que está no domínio físico e que está no domínio electrónico. Como profissionais diferentes e utilizadores diferentes usam artefactos diferentes, são necessários diferentes tipos de dispositivos de input e output, e portanto são necessários tipos muito diferentes de computadores.

Em design, tradicionalmente, sempre foi preciso escolher entre sistemas gerais fracos e sistemas específicos fortes, e este é o conflito que tem dominado todos os aspectos do design, qualquer que seja a área em que se trabalhe.

Vamos ver mais alguns gráficos, em que representamos no eixo vertical o poder de um sistema e no eixo horizontal a sua generalidade.

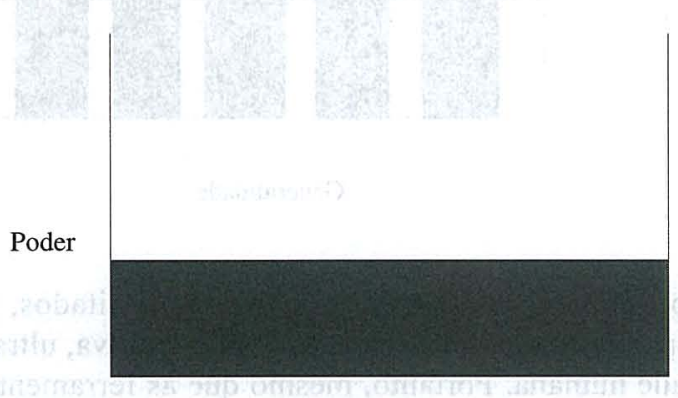

Generalidade

Este é um sistema geral fraco típico. Não é muito poderoso, mas consegue fazer tudo. A área por baixo do gráfico é equivalente à carga cognitiva: é o custo cognitivo do acesso à funcionalidade oferecida pelo sistema.

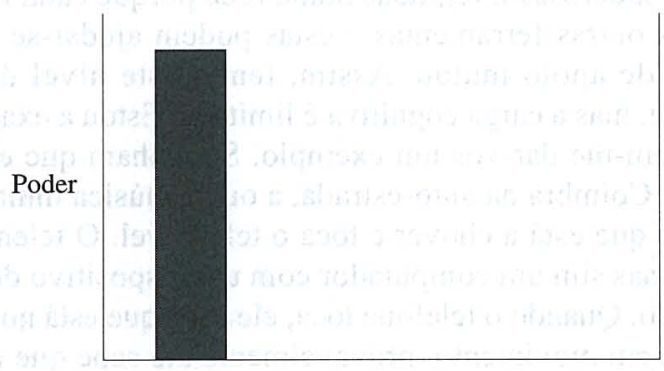

Generalidade 
Este é o outro extremo. Temos aqui um sistema específico forte: notem que a carga cognitiva é menor e que se trata de uma ferramenta melhor, mas infelizmente falta-lhe toda a anterior funcionalidade. Claro que podem perguntar: «Porque é que não se obtém generalidade simplesmente acrescentando umas quantas ferramentas específicas?»

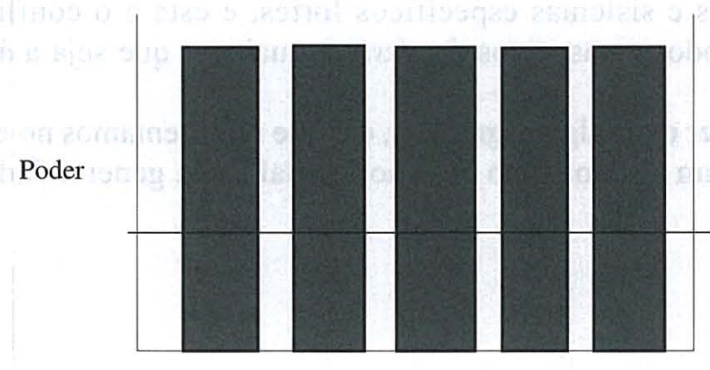

Generalidade

Isto não funciona porque os recursos são limitados, porque a área acumulada por baixo da linha recta, a carga cognitiva, ultrapassa o limiar da capacidade humana. Portanto, mesmo que as ferramentas existam, eu não consigo dominá-las todas de forma a obter o poder funcional completo. E voltamos a um sistema geral fraco ou a um sistema específico forte. A funcionalidade a que eu tenho acesso é limitada pela minha condição humana, ponto final.

É aqui que as coisas estão a mudar, e é esta a diferença entre ontem e amanhã. Mas é também aqui que não estamos a investir o nosso tempo. A minha tese é que há uma vantagem líquida quando se tem ferramentas específicas poderosas integradas numa rede porque cada ferramenta pode conhecer as outras ferramentas e estas podem ajudar-se umas às outras numa base de apoio mútuo. Assim, tenho este nível de poder, tenho generalidade, mas a carga cognitiva é limitada. Estou a exagerar um pouco nisto. Deixem-me dar-vos um exemplo. Suponham que estou a guiar de Lisboa para Coimbra na auto-estrada, a ouvir música muito alto no rádio, e suponham que está a chover e toca o telemóvel. O telemóvel não é um telemóvel, mas sim um computador com um dispositivo de input e output especializado. Quando o telefone toca, ele sabe que está no carro, sabe que o carro está em movimento, provavelmente até sabe que está a chover, e seguramente sabe que o rádio (outro computador) está ligado, e também sabe que não se pode guiar e falar ao telefone e ouvir o rádio ao mesmo 
tempo e que se eu estou a falar ao telefone é perigoso tirar a mão do volante para desligar o rádio. Portanto este computador, por causa da tal vantagem líquida, quando toca desliga o rádio automaticamente. Já há automóveis que fazem isto. O problema interessante não é como fazer isso funcionar porque qualquer pessoa consegue - um estudante consegue fazê-lo mas sim como fazer isso funcionar como um sistema generalizado, de forma que qualquer fabricante (de telefones, de rádios, de automóveis) possa partilhar o seu conhecimento com qualquer outro no mundo e executar essas regras sem ser necessário que isso seja feito e integrado pelo mesmo fabricante. Este é um problema extremamente fascinante de inteligência distribuída e de interligação que ninguém estudou. E é isto que eu designo vantagem líquida.

A coisa mais importante de que podemos beneficiar é que temos o potencial de sair deste dilema geral-fraco / específico-forte, e finalmente ir para sistemas gerais fortes, por causa da vantagem líquida, por causa da colecção de ferramentas interligadas. É isto que é novo, é isto que ninguém nos está a dizer e é isto que ninguém está a investigar.

Em software, a grande moda são as micro-aplicações, chamadas applets (o exemplo típico é a linguagem Java). Eu defendo que ao nível do hardware precisamos de fazer o mesmo tipo de coisas e ter, digamos, micro terminais. Eu chamo-lhes appliancets ${ }^{1}$; é uma palavra muito feia, mas tem uma semelhança agradável com applets. Porque precisamos de fazer isso? $\mathrm{O}$ argumento económico é o seguinte: considere-se uma empresa de alta tecnologia como a Microsoft; para manter Wall Street satisfeita é preciso crescer entre $20 \%$ e $30 \%$ por ano - é preciso fazer isso ou a cotação das acções vai por água abaixo. As coisas são assim, não fui eu que fiz as regras. Ora as vendas de PC crescem entre $13 \% \mathrm{e}$ $15 \%$ ao ano. Não é preciso ser um génio matemático para ver que, se as vendas de PC crescem entre $13 \%$ e $15 \%$, mas a empresa tem de crescer entre $20 \%$ e $30 \%$, há um problema. O problema é que o design e as abordagens actuais não vão sustentar o crescimento para manter a confiança de Wall Street. Algo vai ter de ceder, e o problema para uma empresa como a Microsoft é que ela já tem $90 \%$ do mercado das pessoas que têm um PC. E se pensam que a Microsoft já é grande hoje, imaginem só: ela tem de crescer $20 \%$ ao ano. Que tamanho vão ter dentro de três anos? E como é que vão sustentar esse crescimento se as vendas de PC só crescem entre $13 \%$ e $15 \%$ ? Algo tem de mudar e vai ter de ser o design. Essa é uma das razões por trás deste pequeno Windows, o CE. Mas temos

${ }^{1}$ Do inglês appliance: aparelho, dispositivo. 
de falar mais deste assunto, porque há aqui uma questão realmente interessante: é que fazer estes dispositivos especificos fortes exige um conhecimento profundo no domínio das aplicações. O que vai determinar o sucesso não é sermos bons engenheiros, mas sim o conhecimento no domínio das aplicações, e nenhuma empresa (nem a Microsoft nem nenhuma outra) possui completamente esse conhecimento.

Portanto, ainda que a Microsoft possua a Waternet, é possível conceber um tipo especial de dispositivo ligado à canalização.

Vamos ver alguns exemplos concretos. Antes disso, alguma motivação psicológica. Nada de novo: todos já ouvimos dizer que a notação é uma ferramenta do pensamento. O pensamento gerou a linguagem, a linguagem gerou o pensamento; não pode haver pensamento sem linguagem, não pode haver linguagem sem pensamento.

Por exemplo, uma operação de divisão com números romanos é muito difícil. Quando os Fenícios nos trouxeram a numeração árabe, o mesmo problema (do ponto de vista da carga cognitiva) ficou muito mais simples; até uma criança o consegue resolver.

A notação não é apenas uma coisa visual, não é só linguagem, não é só uma coisa que se escreve. Os objectos podem constituir uma notação. Nos Estados Unidos há um programa estúpido de televisão chamado «Jeopardy». Funciona assim: eu dou-vos a resposta e vocês têm de me dar a pergunta. Eis aqui um relógio. Qual é a pergunta? Muitos pensam que a pergunta é: «Que horas são?» Claro que não acertaram. A pergunta é: «Onde estou?» Pensem um pouco nisto, que é muito importante. Se o Infante D. Henrique tivesse um relógio, imaginem onde Portugal estaria hoje. O mundo é redondo, um dia tem 24 horas; 360 a dividir por 24 dá 15. Portanto, se eu acertei o meu relógio quando o meu barco saiu de Lisboa, só tenho de olhar para o céu e o Sol diz-me quando é o meio-dia. Então olho para o relógio, vejo que horas são e por cada hora de diferença são 15 graus de longitude. Mais nada.

O Almirantado inglês, no período das Descobertas, tinha um prémio de 20000 libras para a primeira pessoa que construísse um relógio preciso e portátil. O livro Longitude, de Dava Sobel, conta esta história. Há uma magnífica história do tempo nesse livro. Mas o que eu vos quero dizer aqui é que o relógio, ou o cronómetro, é uma notação para o problema que teve exactamente a mesma vantagem líquida em termos da representação do problema e da sua solução que a numeração árabe em relação à numeração romana.

A visualização científica e a visualização da informação são técnicas para compreender que um computador é um instrumento notacional par excellence. 
A notação é uma ferramenta do pensamento; um aparelho pode ser uma notação. A coisa mais importante que isto diz, o teste decisivo, é: um design ou uma tecnologia nova faz que seja mais complexo ou mais simples funcionar neste mundo? $\mathrm{E}$ o importante a respeito da tecnologia do relógio foi que a tecnologia da economia, que é claramente uma tecnologia, a tecnologia da construção naval e por aí fora fizeram com que o mundo se tornasse cada vez mais complexo. Ora o design introduziu uma nova tecnologia que tornou aquela tecnologia viável dentro do limiar da frustração.

Foi isso que Samuel Pepys, secretário da Marinha britânico, compreendeu, e é isso que todos nós, designers de computadores, deveríamos ter como objectivo. À medida que o mundo se torna mais complexo, o objectivo da próxima geração, a obrigação da tecnologia da próxima geração é tornar tratáveis os problemas introduzidos pela anterior geração de tecnologias. Tornar o mundo mais simples e fazer a tecnologia desaparecer.

Vamos ver como é que isso se pode fazer. Não se pode fazer isso seguindo a escola de design de Henry Ford. Ele dizia que os carros dele se podiam comprar em qualquer cor que se quisesse desde que fossem pretos; nós dizemos que podemos comprar o computador que quisermos desde que tenha um teclado, um monitor e um rato.

O design ecológico olha para as competências de uma pessoa (competências sociais, cognitivas, motoras e sensoriais) e diz qual é a tecnologia adequada para essas competências nesse momento particular: as ferramentas certas, no lugar certo, para a pessoa certa, no momento certo e da forma certa. O design ecológico é isso.

Vejamos então alguns exemplos. Esta tela electrónica é o meu computador: tenho-o há cinco anos. Um metro por $66 \mathrm{~cm}$ e uma caneta. Eu concebo sistema para artistas, que frequentaram a Escola de Belas-Artes. Perguntem a um artista: qual é para si a coisa mais importante, do ponto de vista da sua identidade? Quando fala a alguém do seu trabalho, o que o faz sentir mais orgulho? É ser capaz de desenhar. E se a capacidade de desenhar é o essencial da sua identidade, quando concebo um computador para ele tenho de respeitar isso. Analogamente, se alguém passa o seu tempo a tocar violino tenho de conceber um computador que respeite isso. Onde está o computador naquela tela? Não há um computador de secretária, não há uma metáfora da secretária - a secretária é o computador e pode desenhar-se com a mesma linguagem corporal e gestual. E também com exactamente o mesmo designer, o mesmo software, o mesmo projecto, o mesmo estúdio: usar este formato da tela de desenho muda completamente a sociologia do estúdio de design porque as pessoas 
começam de novo a ter consciência do trabalho dos outros. Quando visitamos um estúdio de design podemos ver o trabalho de outras pessoas, mas não é educado espreitar por cima do ombro de alguém e portanto não há colaboração no estúdio. Não estamos a falar só de tecnologia: é o mesmo que a ardósia e o quadro; é uma coisa social, cultural, antropológica. Qualquer pessoa das ciências sociais pode explicar porque é que isto funciona, mas como ninguém da informática percebe nada de ciências sociais nunca saberá sequer que há aqui uma pergunta, e muito menos saberá quem pode responder a essa pergunta.

Da mesma forma, pode mudar-se o design do computador para ter um sistema de pintura. Num programa de pintura que data de 1987 o monitor é a tela e temos uma placa, sobre a qual podemos colocar dispositivos que simulam um pincel, um frasco de tinta, uma borracha e um armário arquivador. O menu está nas nossas mãos; é manejável e tangível. Se quero pintar, pego no pincel; se quero apagar, pego na borracha; se quero ir buscar um ficheiro ou guardar alguma coisa, uso o arquivador. Isto acontece porque a placa sabe qual destes dispositivos está sobre ela e portanto o menu está nos dispositivos. Posso assim usar a memória motora e espacial e isto começa a parecer familiar aos artistas.

Fala-se muito de browsers. Eu acredito que no futuro a diversidade dos browsers da Internet será tanta como a diversidade dos browsers de tinta. A expressão «browser de tinta» é uma forma técnica de designar o papel. Pensem em etiquetas, blocos, cartazes, livros, jornais, em qualquer forma de papel com tinta, e podem imaginar a futura diversidade dos browsers. O que é um rádio? Um rádio é um browser; faz buscas no espectro AM, FM de ondas médias ou de ondas longas em vez de as fazer na Internet, mas é um browser. E o que são os botões no vosso auto-rádio? São claramente os bookmarks, tal como no vosso browser.

Isto oferece um exemplo claro de oportunidade. Onde é que se ouve música, nomeadamente rádio? Onde está a vossa colecção de discos? Está ao pé do vosso computador? Não. Então porque é que se há-de esperar que ouçam música no sítio do vosso computador em vez de no sítio da vossa colecção de discos? Portanto, se achamos que ouvir rádio é importante, porque não conceber um browser que só faz rádio? É o sintonizador: funciona como um rádio, tem bookmarks como um rádio e liga-se à aparelhagem da mesma forma que os outros componentes. Costuma-se dizer: «Se parece um pato e se grasna como um pato, é um pato.» $\mathrm{E}$ se parece um rádio e se funciona como um rádio, é um rádio. Não é um computador, não é um browser. E aqui é que bate o ponto: um sintonizador é inútil para verificar as cotações da bolsa, é inútil para 
importar filmes em formato MPEG, mas é exactamente o que pretendem se o que querem é ouvir rádio.

E de facto existe já um produto comercial (ver em www.audible.com) com o qual se pode fazer o download de ficheiros audio para um pequeno aparelho, que depois se traz no bolso e se pode usar para ouvir, seja um curso de línguas, seja outra coisa qualquer.

Qual é o mais importante aparelho interactivo de informação que têm em vossa casa? Não, não é o computador, não é o telefone, não é a televisão. É o frigorífico. Na porta do frigorífico colocamos a agenda do dia, os avisos, a lista das compras... tudo o que precisamos de saber está na porta do frigorífico. E o meu maior problema é que a agenda do meu palmtop não está sincronizada com a do frigorífico. Não me interessa a agenda do meu computador no trabalho; eu quero é estar sincronizado com a minha mulher e os meus filhos. Fora de casa quero poder escrever no ecrã ligado ao meu relógio de pulso e transmitir para a porta do frigorífico: «Querida, vou chegar tarde para o jantar.» Como o meu relógio sabe que se trata de mim e do meu frigorífico, a mensagem segue e a minha mulher verá a mensagem antes de ir ver o correio electrónico, ou o correio de voz, ou o faxe. É mais importante para mim ter o frigorífico ligado à Internet do que o computador.

A porta do frigorífico é um grande ecrã plano. A Fujitsu faz ecrãs planos e também faz frigoríficos. Vai ser possível colar uma figura no ecrã e digitalizá-la, vai ser possível escrever, fazer listas e fazê-las chegar a todas as pessoas da família. Um produto deste tipo existe já no Japão.

Outro exemplo é o Teamboard. Trata-se de um quadro branco parecido com qualquer outro, mas tudo o que se escreve nele é capturado e gravado num computador. Se se equiparem as salas de aula com isto, os estudantes vão ficar com um registo de tudo o que se escrever. Isto é uma ferramenta muito útil e eficaz para arquivar as nossas aulas (inclusive sincronizando o texto e a versão áudio). Ninguém está a produzir isto comercialmente.

O meu novo computador é um clipboard, uma placa com uma mola e uma folha de papel e uma caneta. A caneta tem tinta, mas também tem electrões e consegue transmitir através do papel e a placa lembra-se de tudo o que eu escrevo. E posso ligar a placa ao computador e ficar com uma cópia digital de tudo o que escrevi em 50 folhas de papel. Isto custa 300 dólares. O que é interessante é que foi a IBM que desenvolveu este produto, mas não sabe como vendê-lo. Quem está a ter sucesso a vendê-lo é a Cross, um fabricante de canetas. As pessoas que conceberam aquele quadro branco de que falei há pouco são fabricantes de quadros brancos, não são fabricantes de computadores. São pessoas que compreendem o mercado específico para aquele tipo de tecnologia e são esses que vão 
triunfar. Na linguagem da Waternet, são as pessoas que vão fazer os lavatórios, os chuveiros, etc.

Esta máquina fotográfica, a Coolpix da Nikon, é na realidade um disco rígido. Neste disco rígido escreve-se com luz em vez de pelo bus habitual. Quando se tira uma fotografia pode escrever-se sobre ela, anotar a imagem, e até fazer uma anotação de voz que depois se pode enviar juntamente com a imagem, porque na realidade se trata de um computador. É uma tecnologia muito interessante, a que ninguém vai chamar um computador, apesar de ter muito mais poder computacional do que um Apple 2 ou o primeiro Macintosh.

Quando os computadores sabem onde estão e com quem estão, começamos a poder fazer coisas muito interessantes para conseguir a vantagem líquida de que falei atrás. Já falei de forma, função, localização, competências, etc. Vamos agora falar do modo como estas coisas se articulam.

Hoje os computadores têm muito mais largura de banda do lado do output do que do lado do input. O que eu prevejo é que no futuro haja muito mais input do que output.

Isto já está a acontecer, por exemplo na detecção. A partir das imagens de satélite reunimos informações sobre a Terra e a sua ecologia a uma velocidade inimaginável e não fazemos ideia de como lidar com isso. Mas façamos um zoom. Vamos fazer um zoom sobre uma região, uma cidade, uma casa. E em vez de detecção remota vamos fazer detecção próxima. Isto significa que o meu computador vai agora ter de conhecer a ecologia do local em que se encontra. Tal como os satélites fornecem informações sobre a ecologia do planeta, estes sistemas vão detectar a ecologia - tanto social como física - dos locais próximos. E vamos poder fazer coisas razoáveis com isto porque os sistemas vão ser capazes de compreender o contexto físico e social em que têm lugar as nossas acções e actividades.

Suponham por exemplo que estou carregado de compras do supermercado e estou a dirigir-me para o meu carro. $\mathrm{O}$ meu objectivo principal é transportar as compras para o carro. O supermercado sabe que eu estou carregado e que quero ir para o carro. Como eles querem que eu saia da loja com as minhas compras, abrem-me a porta automaticamente porque sabem que, se eu abrir a porta com a mão, isso vai interferir com a minha capacidade de transportar as compras. A porta é inteligente.

Há tempos tomei o avião nocturno da Califórnia para Toronto, onde ia fazer uma conferência na manhã seguinte. Fiz uma escala em Chicago às $6 \mathrm{~h}$ da manhã. No aeroporto de O'Hare fui à casa de banho e fiquei espantado. $\mathrm{O}$ autoclismo funcionou automaticamente, quando pus as mãos debaixo da torneira a água correu automaticamente, depois fui secar as 
mãos e o ar quente ligou-se automaticamente. Estes aparelhos sabiam o que estavam a fazer; estavam a fazer deteç̧ão próxima.

Agora pensem num computador. Apesar de todos os seus botões e ligações, o meu computador não é tão inteligente como a casa de banho do aeroporto de O'Hare. E eu pergunto: não deveria o meu computador ser tão inteligente como uma casa de banho?

Vamos então tentar conceber computadores tão inteligentes como as nossas casas de banho. Um exemplo é o rato-na-porta, que foi uma ideia brilhante de um dos meus estudantes. Uma situação que eu detesto é receber alguém no meu gabinete para uma conversa privada e mal fecho a porta o telefone toca. Nunca consegui aprender a redireccionar as chamadas para o gabinete da minha secretária e, mesmo que soubesse, no fim da conversa esquecia-me de voltar a ligar o telefone para mim. Mas agora reparem: peguem num rato de computador, aparafusem-no sem a tampa na parede ao pé da porta e façam uma ligação entre a dobradiça da porta e o mecanismo do rato. Quando a porta se abre, a dobradiça roda, este movimento transmite-se ao rato, que o transmite ao meu computador, e assim o meu computador sabe se a porta está aberta ou fechada. E eu tenho uma vantagem líquida porque o meu computador controla o telefone e também as minhas vídeo-conferências e os meus chats. Eu só tenho um mecanismo social para controlar a privacidade, que é a porta. Se eu trago a auto-estrada da informação até mim, quero um sinal de paragem, um semáforo, e já tenho um, que se chama a minha porta. Portanto agora, quando fecho a porta, fecho-a não só para o corredor físico, mas também para o corredor electrónico, e tenho um mecanismo unificado, que já existia em virtude das minhas competências sociais, que funciona para ambas as coisas. O meu mundo ficou mais simples, o telefone já não toca quando eu tenho a porta fechada e quando abro a porta torno a abrir o corredor. E posso sempre contornar isto para as situações especiais em que há barulho lá fora mas mesmo assim quero que as pessoas entrem. Aqui está mais um exemplo de vantagem líquida, através de detecção próxima. O que isto diz é que a porta do meu gabinete é um dispositivo de input para o meu computador tão legítimo como um rato ou um teclado. Isto é design ecológico.

Outro exemplo é uma câmara de vídeo montada verticalmente sobre a minha secretária. Não preciso daquelas luvas estúpidas ou de pôr capacetes com visores na cabeça; o computador olha através da câmara, olha para o display onde se está a trabalhar. Pode ver a mão a mover-se, pode fazer reconhecimento simples de formas e perceber onde está a mão, reconhecer tamanhos, sobreposições. E com esta visão simples eu posso pegar nas coisas, movê-las, esticá-las, etc. Há um artista que trabalha com 
isto há 15 anos. Não há nenhum sistema comercial que faça nada de parecido. De novo, não há aqui nenhum computador de secretária, nenhuma das coisas habituais do interface gráfico. É nisto que um estudante de pós-graduação devia pensar, neste tipo de problemas. Se uma coisa se parece com algo que já viram antes, não é melhor irem por aí porque isso não tem interesse. Se a tecnologia resolve o problema em cinco anos, é investigação estúpida. É engenharia, deixem os engenheiros fazer isso.

Ainda mais um exemplo: a vídeo-conferência em grupo. Pode conceber-se um sistema em que se respeitem as interacções individuais. Se estiverem quatro pessoas ligadas, podem usar sensores de proximidade de forma a preservar todas as convenções sociais de uma conversa presencial. Se eu me inclino para o terminal relativo a uma das pessoas, o microfone desliga-se para as outras e posso ter uma conversa privada. $\mathrm{E}$ as outras duas pessoas podem conversar em simultâneo. Claro que se não compreendermos as coisas básicas - psicologia, sociologia - sobre a estrutura de uma reunião, não podemos conceber tecnologias para $o$ trabalho em colaboração. Tudo tem de estar centrado nas pessoas.

Vou terminar isto com um modelo simples. Se um modelo for mais complexo do que a realidade que pretende explicar, não será muito útil. A ciência está cheia de modelos que são mais complexos, ou têm tanta probabilidade de conter erros como o fenómeno que pretendem descrever. Não gosto disso e portanto faço modelos muito simples.

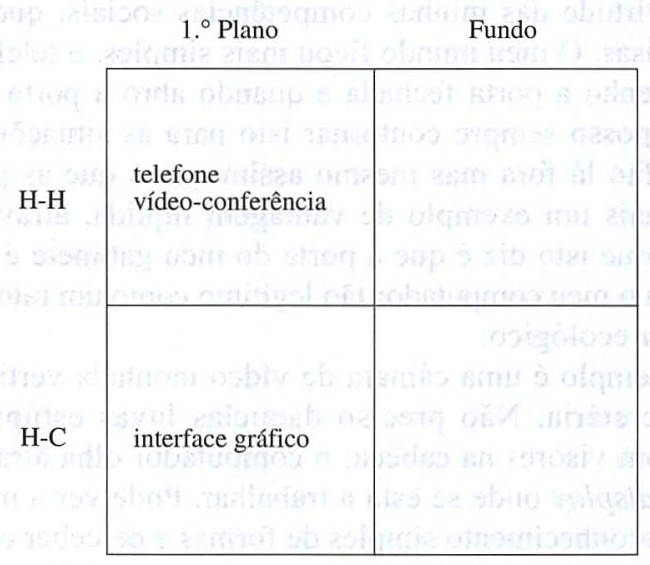


Isto é basicamente o mundo da tecnologia, a forma como se articulam as telecomunicações e os computadores. A primeira linha representa a interacção homem-homem através da tecnologia; a segunda linha representa a interacção homem-computador ou homem-máquina; a primeira coluna representa o primeiro plano; e a segunda coluna representa o plano de fundo. Quase toda a nossa actividade em telecomunicações existe no quadrante superior esquerdo (o telefone, a vídeo-conferência, etc.) e quase toda a interacção homem-máquina existe no quadrante inferior esquerdo (interfaces gráficos, etc.). Mas se recordarem tudo o que eu disse até agora, podem concluir que eu acredito que a segunda coluna é onde está a acção, é a ela que devemos dedicar o nosso tempo, é a área não explorada. Quem quiser ser um dos descobridores (lembrem-se de que estamos em Portugal) deve ir para a segunda coluna.

Para dar alguns exemplos: os objectos caseiros inteligentes, o rato na porta, a casa de banho no aeroporto de O'Hare, o telefone e o rádio do carro, todos eles pertencem ao quadrante inferior direito, plano de fundo e interacção homem-máquina.

E o quadrante superior direito? Vou dar-vos um exemplo: o programa Postcards. O que este programa faz em plano de fundo é usar a câmara montada por cima do monitor do computador para, uma vez por minuto, enviar uma imagem de cada pessoa para todos os membros de um grupo de pessoas. Estas imagens são pequenos retratos que não violam a privacidade e as únicas pessoas que podem olhar para eles são as pessoas na minha rede social imediata: as pessoas com quem eu interajo diariamente, os meus colegas mais próximos, mas que estão espalhados por todo o mundo. O que isto significa é que, quando entro no meu gabinete na Califórnia posso ver se Bill Gaber, que está em Inglaterra e com quem estou a escrever um livro, já se foi embora, porque quando são $9 \mathrm{~h}$ da manhã na Califórnia são $5 \mathrm{~h}$ da tarde em Cambridge. Se ele ainda lá estiver, posso simplesmente telefonar-lhe. Portanto, posso estar a trabalhar e ver a minha periferia social.

Eis alguns factos básicos da sociologia do local de trabalho. Para pessoas que trabalham no mesmo andar, $90 \%$ das reuniões não são previamente marcadas, não têm hora certa, duram menos de três minutos e envolvem mais de duas pessoas. Para pessoas que trabalham em andares diferentes, ou em edifícios diferentes, as reuniões tendem a ser marcadas com uma semana de antecedência e a durar horas. Portanto, como acreditamos que a interacção próxima é importante, estamos a tentar construir aqui uma prótese social. O Postcards é uma prótese cognitiva ou social. Mesmo que estejam em Portugal e eu em Toronto, podemos ter o mesmo tipo de consciência da nossa periferia social. 
Duas destas imagens seguidas constituem um sensor de movimento. Se comparo duas imagens e $40 \%$ dos pixels mudaram, sei que alguma coisa aconteceu. Assim, olhando só para um bit de status, sei se uma pessoa ainda lá está, se entrou ou se saiu. Se eu quiser mesmo ter uma reunião com Kimiya Yeemashi no Japão, Tracy em Toronto e Jeremy em Montreal, limito-me a carregar no botão «Detectar» e quando todos estamos nos nossos gabinetes as nossas portas estão abertas e não estamos ao telefone (porque podemos saber todas essas coisas) podemos iniciar uma conversa.

A própria conversa pode ser pelo telefone, não precisamos de vídeo-conferência. Ter a reunião é fácil; o problema é conseguir fazer a reunião acontecer. Quando desperdiçamos tempo, precisamos de uma prótese.

Deste modo não se trata só de preencher aqueles quatro quadrantes, trata-se também de estabelecer ligações eficazes entre eles. A transacção que acabo de descrever a propósito da reunião é um exemplo de todas essas ligações.

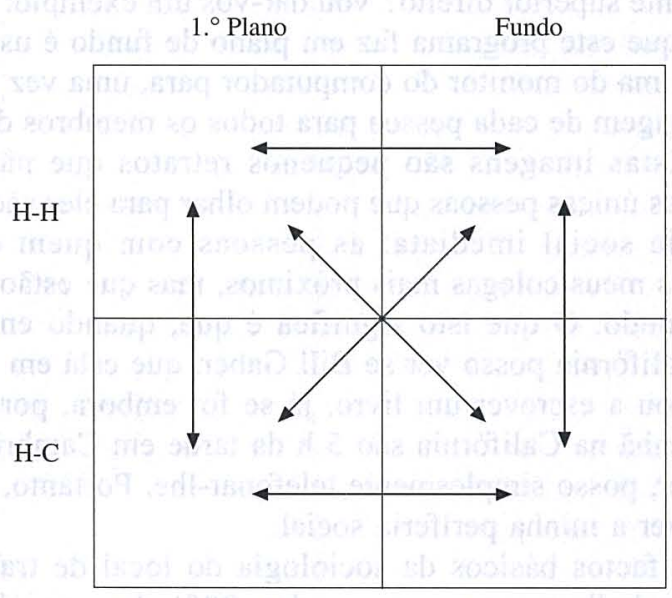

No meu último exemplo, o fundo funciona ao mesmo tempo que o primeiro plano, para apoiar a acção. Pensem numa máquina fotográfica Nikon $F$, que é uma espécie de MS-DOS ou Unix das máquinas fotográficas. Podem tirar todas as fotografias imagináveis, mas a probabilidade de qualquer fotografia sair bem é muito baixa, a menos que se seja um especialista. Do ponto de vista da ciência cognitiva, quais são as duas 
únicas decisões de primeira ordem na fotografia? «O quê» e «quando». E estas duas decisões de primeira ordem traduzem-se em duas acções de primeira ordem: apontar e disparar. Tudo o resto é secundário ou acessório.

Mas esta nova máquina fotográfica, este computador a que chamamos máquina fotográfica, sabe que a única coisa para que a vamos utilizar é tirar fotografias, e portanto pode usar detecção próxima para perceber o contexto e ser especialista no seu domínio de aplicação. Eu só tenho de pensar nas duas questões de primeira ordem (apontar e disparar) e a máquina fará tudo o resto porque compreende a morfologia básica da fotografia. Com uma máquina melhor posso passar por cima disso, mas não sou obrigado a fazê-lo.

À medida que começamos a fazer estas appliancets, a explorar a vantagem líquida e a ter apoio de fundo e de primeiro plano podemos integrar o conhecimento específico nestes aparelhos de forma que o utente só tenha de se preocupar com as decisões de primeira ordem, e as de segunda ordem sejam voluntárias. É este tipo de tecnologia, este tipo de análise de sistemas que temos de começar a ensinar e a aplicar nos nossos designs. A razão por que este objecto não é visto senão como uma máquina fotográfica é que este computador não está sujeito a nenhuma crise de identidade: sabe que existe para tirar fotografias; é um computador em que o input, em vez de ser feito através de um rato, é luz e o output não é transmitido através de um monitor mas de bits ou de uma reacção química. E mesmo uma máquina fotográfica que usa um rolo tem lá dentro mais poder computacional do que um Apple 2.

Ora isto não vale só para máquinas fotográficas. Pensem num scanner. Uma tarefa como, carregando só num botão, digitalizar um livro e gravar o resultado no disco rígido é impossível. Porquê? Porque o scanner não sabe que é um scanner, o scanner não percebe nada de digitalização.

Mas se um scanner serve para digitalizar documentos, porque é que não percebe nada da morfologia de documentos, como esta máquina fotográfica percebe de luz? Quais são as três decisões de primeira ordem na digitalização? O que vou digitalizar, quando vou fazê-lo, para onde vai o resultado. Estas são as únicas três coisas que nos deviam preocupar. Se esta tecnologia estivesse madura e se pudesse integrar este conhecimento sobre documentos no scanner, quando aí colocássemos o documento ele diria: «Ah, é uma fotografia a cores, vou usar 24 bits por pixel», ou «É uma fotografia a preto e branco, vou usar 8 bits por pixel», ou «É texto, vou usar um bit por pixel». Depois de fazer isso e de ter conseguido uma grande compressão de dados sem ter feito compressão nenhuma, dirá: «Como é texto, vou fazer reconhecimento de caracteres e pô-lo em ASCII, e nas imagens a cores vou usar JPEG». Em seguida o 
resultado vai para o disco e tudo funcionará à primeira porque com detecção próxima, conhecimento integrado e esta noção de dispositivos específicos fortes podemos reduzir a complexidade de forma que até a nossa avó conseguiria digitalizar um documento. É essa a ideia.

Resumindo: temos feito um péssimo trabalho com os computadores e a tecnologia. Essas são as más notícias. As boas notícias são que isto não é difícil de corrigir. Temos de mudar a nossa maneira de pensar os computadores, temos de mudar a nossa maneira de pensar os aparelhos e temos de começar a perceber que as pessoas são mais importantes do que a tecnologia. $\mathrm{Ou}$, dito de outra forma, à maneira de um engenheiro: as pessoas são a tecnologia que interessa e não se pode construir uma prótese se não se compreende a função que ela tem de realizar. É tempo de começar a treinar os nossos estudantes e os nossos professores para compreenderem como isso se faz. E, se o fizermos, talvez venhamos a descobrir que há coisas simples que se podem fazer que terão o mesmo impacto que a passagem da ardósia para o quadro. 
(Página deixada propositadamente em branco) 
 \\ A palavra "fronteiras" pode ser tomada em} diferentes sentidos. Pode referir-se aos limites, necessariamente provisórios, entre o conhecido e o desconhecido, ou aos limites entre o possivel e o impossivel, e, dentro do possivel, entre o desejável e 0 indesejável. Fronteiras podem também ser as delimitações, nem sempre nítidas, entre ciência e não-ciência, e dentro da ciência, entre as várias disciplinas. Quais são então as fronteiras da ciência?

Neste livro, a resposta a esta pergunta é dada, segundo as mais diferentes perspectivas, por um conjunto notável de personalidades, cientistas ou não, entre as quais se contam três Prémios Nobel.

Rui Fausto, Carlos fiolhais e JoÃo Fillipe Queiró são, respectivamente, professores de Química, Física e Matemática na Faculdade de Ciências e Tecnologia da Universidade de Coimbra. 